\title{
Clinical Characteristics of Patients With Acute Myocardial Infarction Who Did Not Undergo Primary Percutaneous Coronary Intervention - Report From the MIYAGI-AMI Registry Study -
}

Kiyotaka Hao, MD, PhD; Jun Takahashi, MD, PhD; Kenta Ito, MD, PhD; Satoshi Miyata, PhD; Taro Nihei, MD, PhD; Kensuke Nishimiya, MD, PhD; Ryuji Tsuburaya, MD, PhD; Yasuharu Matsumoto, MD, PhD; Yasuhiko Sakata, MD, PhD; Satoshi Yasuda, MD, PhD; Hiroaki Shimokawa, MD, PhD on behalf of the MIYAGI-AMI Registry Study Investigators

\begin{abstract}
Background: In the current era of primary percutaneous coronary intervention ( $\mathrm{PCl})$, some patients with acute myocardial infarction (AMI) still do not undergo primary $\mathrm{PCl}$.

Methods and Results: To examine the clinical characteristics of AMI patients who did not undergo primary PCI, we analyzed patients enrolled between 2002 and 2010 in the MIYAGI-AMI Registry Study, in which all AMI patients in the Miyagi prefecture have been prospectively registered. Among a total of 8,640 patients, 1,879 (21.7\%) did not undergo primary $\mathrm{PCl}$ and their in-hospital mortality was significantly worse compared with those who did $(21.4 \%$ vs. $6.4 \%, \mathrm{P}<0.01)$. Multivariate analysis demonstrated that female sex was significantly associated with non-performance of primary $\mathrm{PCl}$ [odds ratio (95\% confidence interval): 1.40 (1.22-1.61), $\mathrm{P}<0.001$ ], along with age [1.01 (1.01-1.02), $\mathrm{P}<0.001]$ and heart failure on admission [2.69 (2.29-3.16), $\mathrm{P}<0.001]$. When dividing by age, the nonperformance rate of primary $\mathrm{PCl}$ in females showed a $\mathrm{U}$-shaped prevalence, whereas it simply increased with aging in males. Importantly, female patients aged $<80$ years had a significantly higher non-performance rate of primary $\mathrm{PCl}$ compared with male patients, regardless of the severity of AMI.
\end{abstract}

Conclusions: These results indicate that in the current $\mathrm{PCl}$ era, various factors, including aging, heart failure on admission and sex differences, are associated with non-performance of primary $\mathrm{PCI}$, which remain to be resolved in order to further improve critical care of AMI. (Circ J 2015; 79: 2009-2016)

Key Words: Acute myocardial infarction; Percutaneous coronary intervention; Sex differences

A cute reperfusion therapy with fibrinolytic therapy or primary percutaneous coronary intervention (PCI) reduces mortality from acute myocardial infarction $(\mathrm{AMI}),{ }^{1-3}$ and guidelines from Europe and the United States have emphasized the need for identifying patients to minimize delays in the delivery of reperfusion therapy.,5 In addition, previous clinical trials have suggested that primary PCI has some advantages over fibrinolysis in patients who are eligible for either treatment. ${ }^{2,6-10}$ Nevertheless, even in the current PCI era, only $40 \%$ of patients with ST-segment elevated myocardial infarction (STEMI) undergo primary PCI in Western countries, so a considerable number of patients still do not. ${ }^{11,12}$
On the other hand, in Japan with its relatively narrow territory and hence good access to hospitals, the performance rate of primary PCI in patients with AMI has dramatically increased during the $1990 \mathrm{~s}$, and currently more than $80 \%$ of AMI patients undergo the therapy, ${ }^{13,14}$ which is extremely high as compared with other Western countries. However, a certain number of AMI patients still do not undergo primary PCI in Japan and their clinical characteristics remained to be elucidated to further improve the critical care of AMI.

\section{Editorial p1900}

Received April 21, 2015; revised manuscript received May 29, 2015; accepted May 31, 2015; released online June 25, 2015 Time for primary review: 15 days

Department of Cardiovascular Medicine, Tohoku University Graduate School of Medicine, Sendai (K.H., J.T., K.I., S.M., T.N., K.N., R.T., Y.M., Y.S., H.S.); Department of Cardiovascular Medicine, National Cerebral and Cardiovascular Center, Suita (S.Y.), Japan

The Guest Editor for this article was Kazuo Kimura, MD.

Mailing address: Hiroaki Shimokawa, MD, PhD, Professor and Chairman, Department of Cardiovascular Medicine, Tohoku University Graduate School of Medicine, Seiryo-machi, Aoba-ku, Sendai 980-8574, Japan. E-mail: shimo@cardio.med.tohoku.ac.jp

ISSN-1346-9843 doi:10.1253/circj.CJ-15-0440

All rights are reserved to the Japanese Circulation Society. For permissions, please e-mail: cj@j-circ.or.jp 


\begin{tabular}{|c|c|c|c|c|}
\hline & Overall & With primary $\mathrm{PCI}$ & Without primary $\mathrm{PCl}$ & \\
\hline & $n=8,640$ & $n=6,761(78.3 \%)$ & $n=1,879(21.7 \%)$ & $P$ value \\
\hline Age, median (IQR) & $70(60-79)$ & $69(59-78)$ & $73(63-83)$ & $<0.001$ \\
\hline Female (\%) & 28.2 & 25.7 & 37.1 & $<0.001$ \\
\hline Hypertension (\%) & 60.7 & 61.6 & 57.7 & 0.002 \\
\hline Diabetes (\%) & 34 & 34.3 & 33.1 & 0.313 \\
\hline Dyslipidemia (\%) & 37.7 & 40.1 & 29.1 & $<0.001$ \\
\hline Smoking (\%) & 32.2 & 34.3 & 24.7 & $<0.001$ \\
\hline Prior infarction (\%) & 10.1 & 9.4 & 12.7 & $<0.001$ \\
\hline Anterior AMI (\%) & 45.4 & 46.0 & 43.4 & 0.047 \\
\hline Onset at night (19:00-07:00 hours) (\%) & 44.2 & 43.3 & 47.5 & 0.004 \\
\hline Ambulance use (\%) & 68.4 & 70.1 & 62.2 & $<0.001$ \\
\hline Elapsed time from onset to admission (h) & & & & $<0.001$ \\
\hline$\leq 2$ & 31.8 & 32.4 & 29.6 & \\
\hline $2-6$ & 34.1 & 35.1 & 30.5 & \\
\hline $6-24$ & 20.2 & 20.1 & 20.6 & \\
\hline$\geq 24$ & 14.0 & 12.5 & 19.3 & \\
\hline HF with Killip class $\geq 2$ on admission (\%) & 11.9 & 8.7 & 23.2 & $<0.001$ \\
\hline In-hospital mortality (\%) & 9.7 & 6.4 & 21.4 & $<0.001$ \\
\hline
\end{tabular}

$\mathrm{AMI}$, acute myocardial infarction; $\mathrm{HF}$, heart failure; $\mathrm{PCl}$, primary percutaneous coronary intervention.

In order to explore the annual trend for AMI in Japan, we have been conducting the MIYAGI-AMI Registry Study for 35 years since 1979, in which almost all AMI patients in the Miyagi prefecture, which is located in northeastern Japan, have been prospectively registered. ${ }^{13,15-17}$ Because the Miyagi prefecture has a typical balance of urban and rural areas, and the MIYAGI-AMI Registry Study includes a wide variety of hospitals, we could perform an unbiased study concerning the critical care of AMI patients in Japan. Thus, in the present study, we aimed to elucidate the clinical characteristics of AMI patients registered in the MIYAGI-AMI Registry Study who did not undergo primary PCI in the current PCI era.

\section{Methods}

This study was approved by the Institutional Review Broad of Tohoku University Graduate School of Medicine under the condition that personal data were protected at all times.

\section{The MIYAGI-AMI Registry Study and Study Populations}

The MIYAGI-AMI Registry Study is a prospective, multicenter and observational study. As previously reported, ${ }^{13,15-18}$ the registry was established in 1979 to explore the annual trend for AMI in Japan and all 45 hospitals with a coronary care unit and/or cardiac catheterization facility in Miyagi prefecture have been participating (Appendix). In the Miyagi prefecture with a population of approximately 2.33 million and an area of $7,286 \mathrm{~km}^{2}$, almost all AMI patients are transferred to one of the participating hospitals via the emergency medical service. The diagnosis of AMI was based on the WHO-MONICA criteria, including typical severe chest pain accompanied by abnormal ECG changes and increased serum levels of cardiac enzymes. ${ }^{19}$ Thus, in the present study, both STEMI and nonSTEMI (NSTEMI) patients were enrolled with no distinction. Treatments, including reperfusion therapies, were left to the discretion of individual cardiologists in charge.

In the present study, we analyzed a total of 8,640 AMI patients registered in the MIYAGI-AMI Registry Study dur- ing the period between 2002 and 2010, when primary PCI with stents was established as the first-line therapy of recanalization and the performance rate of primary PCI reached a plateau of approximately $80 \%$ as previously reported..$^{13,15}$

\section{Statistical Analysis}

To examine the determinants of non-performance of primary PCI, we performed multivariate logistic regression analysis and calculated the odds ratios (OR) and $95 \%$ confidence intervals $(95 \% \mathrm{CI})$. The following variables were examined in the logistic regression model: age; sex; history of hypertension, diabetes mellitus and dyslipidemia; current smoking; prior MI; infarction site (anterior or not); onset at night (19:00-07:00 hours); ambulance use for admission; elapsed time from symptom onset to admission $(\leq 2 ; 2-6 ; 6-24$; and $\geq 24 \mathrm{~h})$; and coexisting heart failure (HF) with Killip class $\geq 2$ on admission. In addition, we performed the same analysis in the subgroups divided by sex and age: male patients aged $<80$ years; female patients aged $<80$ years; male patients $\geq 80$ years; and female patients $\geq 80$ years.

Furthermore, to address the influence of sex and age in nonperformance of primary PCI, all patients were divided into 5 age groups ( $\leq 59,60-69,70-79,80-89$, and $\geq 90$ years), and sex difference was examined in terms of non-performance rate of primary PCI, coexisting HF with Killip class $\geq 2$, in-hospital mortality and percentage of patients admitted within $24 \mathrm{~h}$ of onset. Moreover, to assess the factors associated with sex difference by age groups in non-performance of primary PCI, we analyzed the patients by the presence or absence of coexisting HF with Killip class $\geq 2$, death during hospitalization, elapsed time $\geq 24 \mathrm{~h}$ from onset to admission, and study period (20022004, 2005-2007, and 2008-2010).

We applied the Mann-Whitney test for continuous values and the chi-square test for categorical variables. Continuous variables are expressed as median and interquartile range (IQR). $\mathrm{P}<0.05$ was considered statistically significant. All statistical analyses were performed using the statistical software SPSS statistics 20 (IBM Corp, Armonk, NY, USA). 


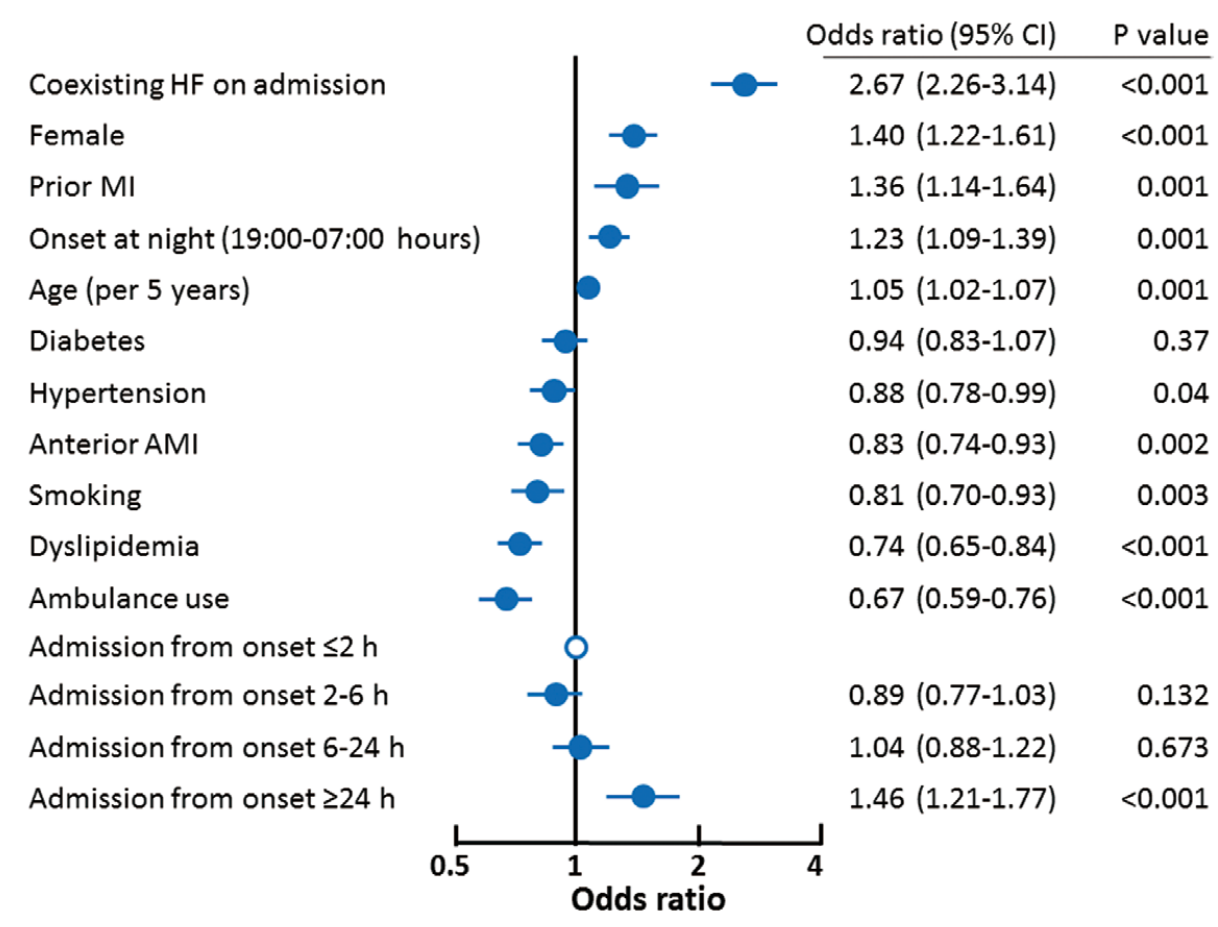

Figure 1. Multivariate analysis of the determinants of non-performance of primary percutaneous coronary intervention. Cl, confidence interval; MI, myocardial infarction.

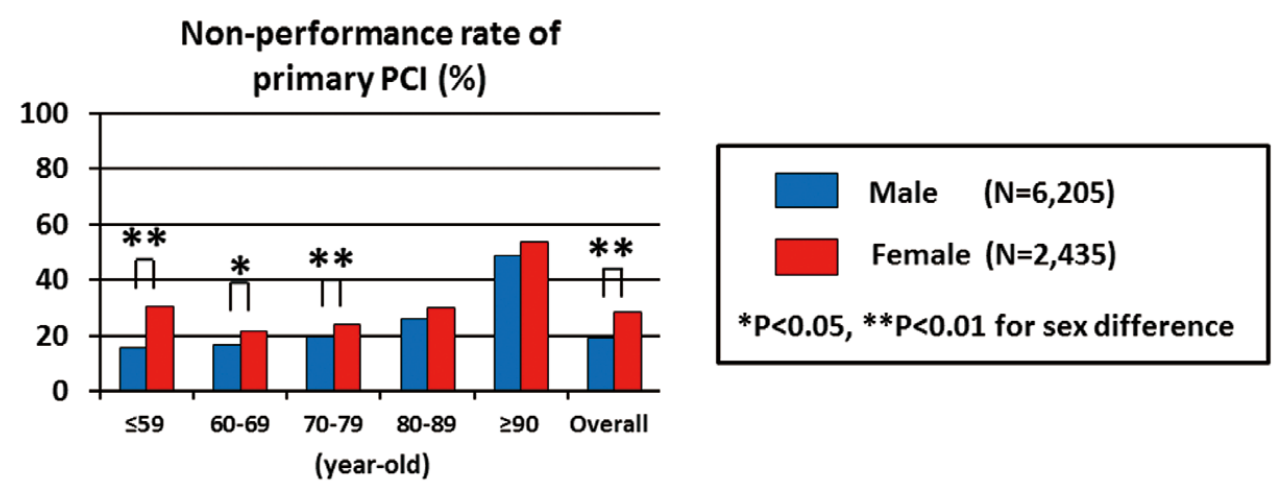

Figure 2. Sex differences in the non-performance rate of primary percutaneous coronary intervention (PCI) in Japanese acute myocardial infarction (AMI) patients by age. The non-performance rate of primary $\mathrm{PCl}$ in female patients showed a U-shaped prevalence, whereas it simply increased with age in male patients.

\section{Results}

\section{Baseline Characteristics and Outcomes}

In the present study, a total of 8,640 patients with AMI registered from 2002 to 2010 were analyzed. They were predominantly male $(71.8 \%)$ and the median age was 70 years. Baseline characteristics and outcomes of the patients subdivided according to the presence or absence of performance of primary PCI are summarized in Table. Among all subjects, 1,879 (21.4\%) did not undergo primary PCI. Of those, 353 patients received fibrinolytic therapy. In the patients who did not undergo primary PCI, in-hospital mortality was significantly worse than for those who had PCI $(21.4 \%$ vs. $6.4 \%, \mathrm{P}<0.001)$, and the clinical characteristics also varied markedly between the 2 groups with and without primary PCI. The patients without primary PCI were characterized by advanced age, female sex and previous MI, whereas those with primary PCI showed a higher prevalence of dyslipidemia and current smokers. Moreover, the patients without primary PCI had a longer time from onset to admission and a higher prevalence of HF with Killip 


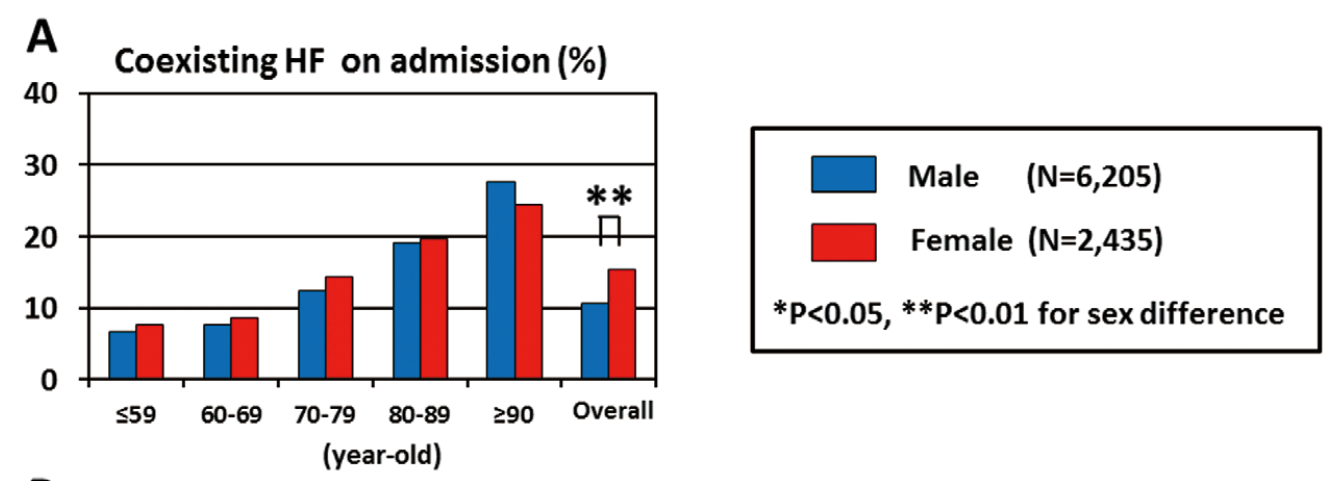

B Non-performance rate of primary PCl (\%)
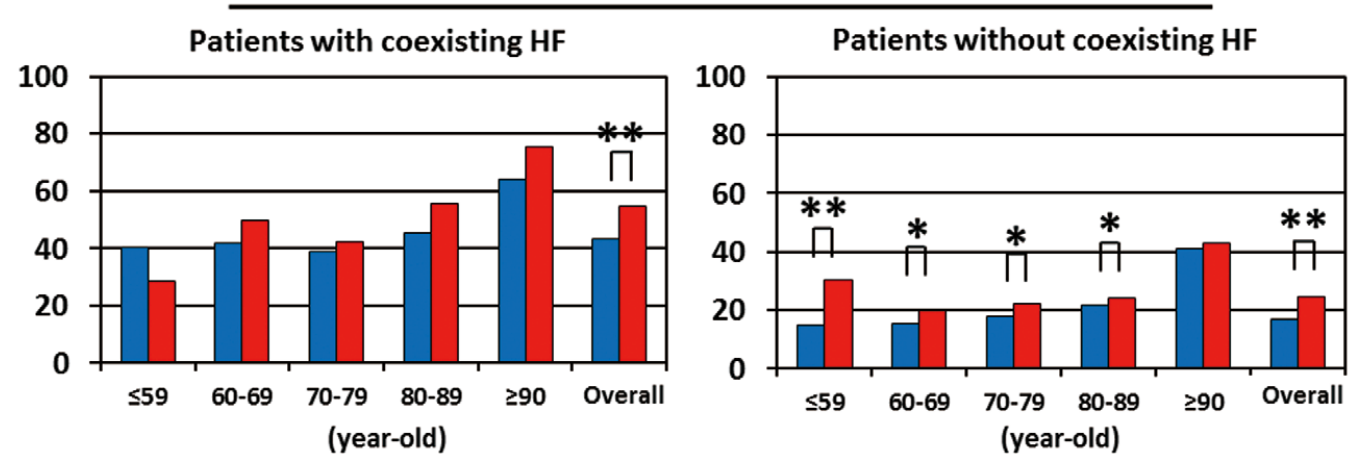

Figure 3. Sex differences in the non-performance rate of primary percutaneous coronary intervention (PCI) and coexisting heart failure (HF) on admission. (A) Prevalence of coexisting HF with Killip class $\geq 2$ on admission increased with aging in both sexes. (B) When dividing the patients into 2 groups according to coexisting HF on admission, the sex difference in non-performance rate of primary $\mathrm{PCl}$ in younger populations was observed only in patients without coexisting HF on admission.

class $\geq 2$ on admission (both $\mathrm{P}<0.001$ ).

\section{Factors Associated With Non-Performance of Primary PCI}

To explore the factors associated with non-performance of primary PCI, we performed multivariate logistic regression analysis and the results are shown in Figure 1. Covariates associated with non-performance of primary PCI included, in the order of $\mathrm{OR}$, coexisting HF with Killip class $\geq 2$ on admission [OR (95\% CI); 2.67 (2.26-3.14), $\mathrm{P}<0.001]$, admission $\geq 24 \mathrm{~h}$ of the onset of symptoms [OR $(95 \% \mathrm{CI}) ; 1.46(1.21-$ 1.77), $\mathrm{P}<0.001$ ], female sex [OR (95\% CI); 1.40 (1.22-1.61), $\mathrm{P}<0.001]$, prior MI [OR (95\% CI); $1.36(1.14-1.64), \mathrm{P}=0.001]$, onset at night (19:00-07:00 hours) [OR (95\% CI); 1.23 (1.09$1.39), \mathrm{P}=0.001]$, and age [OR for age per 5 years $(95 \% \mathrm{CI})$; 1.05 (1.02-1.07), $\mathrm{P}<0.001$ ] (Figure 1). In contrast, covariates associated with performance of primary PCI included use of ambulance [OR (95\% CI); 0.67 (0.56-0.76), P<0.001], dyslipidemia [OR (95\% CI); $0.74(0.65-0.84), \mathrm{P}<0.001]$, current smoking habit [OR (95\% CI); $0.81(0.70-0.93), \mathrm{P}=0.003]$ and anterior AMI [OR (95\% CI); 0.83 (0.74-0.93), $\mathrm{P}=0.002$ ] (Figure 1).

\section{Non-Performance Rate of Primary PCI by Age and Sex}

When we analyzed the patients by age groups, the non-performance rate of primary PCI in male patients simply increased with aging, whereas it showed a U-shaped prevalence in female patients (Figure 2). Moreover, female patients had significantly higher non-performance rate of primary PCI than male patients in the 3 younger age groups $(\leq 59,60-69,70-79$ years old: $\mathrm{P}<0.01, \mathrm{P}<0.05$ and $\mathrm{P}<0.01$, respectively). Especially, in the youngest group ( $\leq 59$ years), the sex difference in non-performance rate of primary PCI was consistently noted during the study period (Figure $\mathbf{S 1}$ ). In contrast, the prevalence of coexisting HF with Killip class $\geq 2$ on admission simply increased with aging in both sexes (Figure 3A). Figure 4 shows the results of multivariate analysis in the subgroups classified by sex and age 80 years. In both male and female elderly patients aged $\geq 80$ years, older age was significantly associated with increased non-performance rate of primary PCI [adjusted OR for age (95\% CI); 1.52 (1.20-1.93), $\mathrm{P}<0.001$ in males aged $\geq 80$ years, $1.66(1.38-1.99), \mathrm{P}<0.001$ in females aged $\geq 80$ years]. In contrast, among the patients aged $<80$ years, the sex difference on the influence of aging was evident, with a negative correlation with non-performance of primary PCI in female patients [adjusted OR for age $(95 \%$ CI); 0.91 (0.84-0.98), $\mathrm{P}=0.02$ ] but not in male patients. In contrast, coexisting HF with Killip class $\geq 2$ on admission was consistently associated with non-performance of primary PCI regardless of age or sex (Figure 4).

Finally, we performed subgroup analysis of the patients in 2 groups according to coexisting $\mathrm{HF}$ on admission. Interestingly, the U-shaped prevalence of non-performance of primary PCI by age strata was evident only for female patients without HF on admission (Figure 3B). Similar findings were also noted when dividing the patients into 2 groups according to in-hospital mortality (Figure 5) and the elapsed time at 


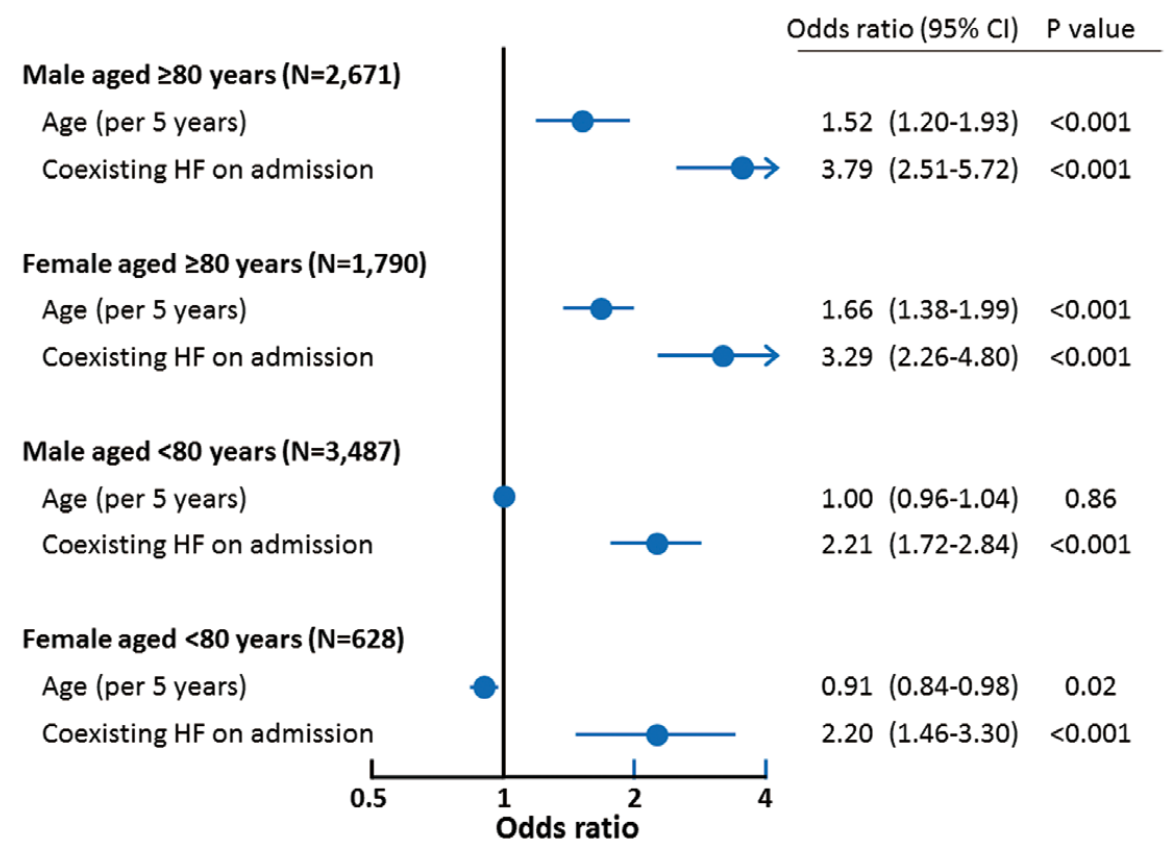

Figure 4. Adjusted odds ratio of non-performance of primary percutaneous coronary intervention (PCI) in subgroups divided by age and sex. Only among female patients aged $<80$ years was younger age significantly associated with non-performance of primary PCI. In contrast, coexisting heart failure (HF) on admission was significantly associated with non-performance of primary $\mathrm{PCl}$ in all groups. Odds ratio was adjusted by the same factors as in Figure 1. Cl, confidence interval.
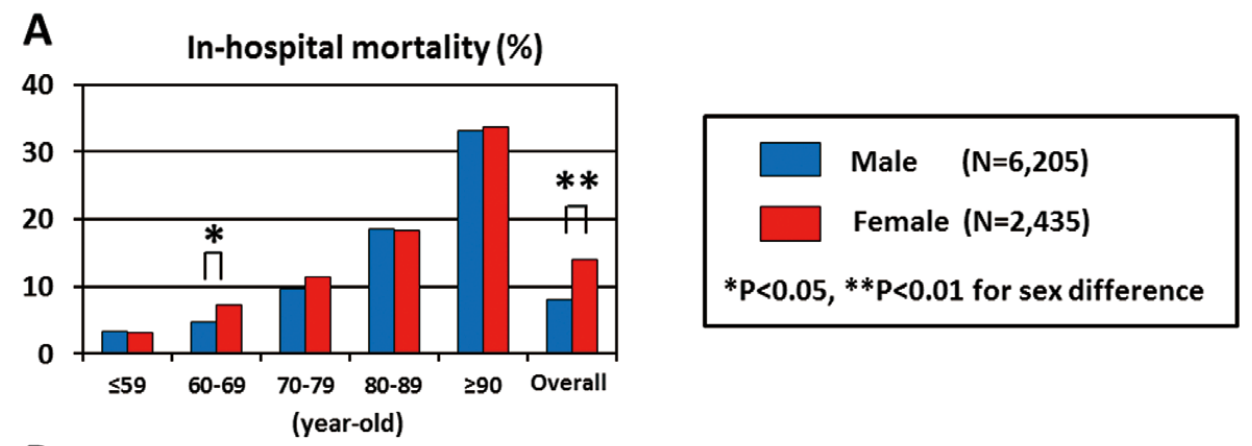

B

Non-performance rate of primary $\mathrm{PCl}(\%)$
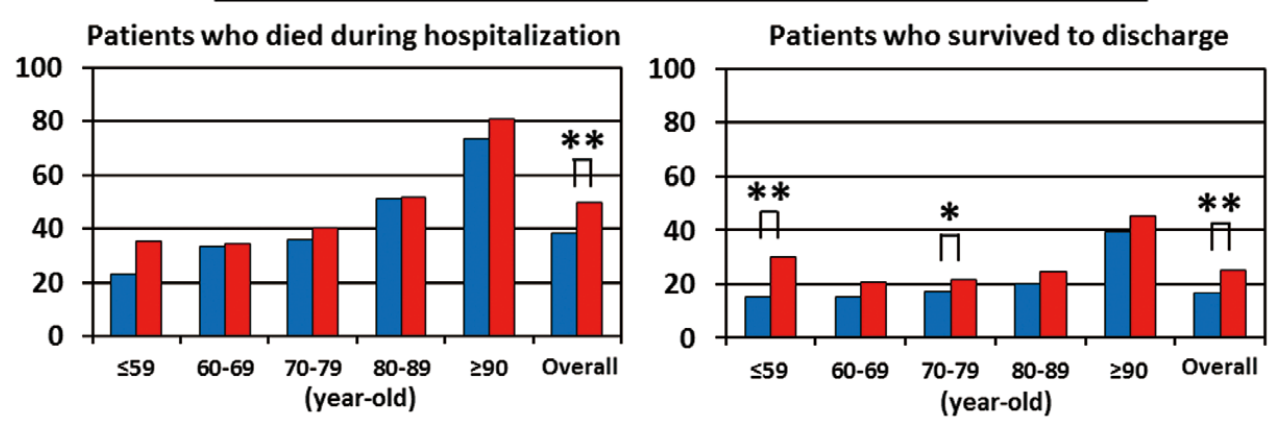

Figure 5. Sex differences in the non-performance rate of primary percutaneous coronary intervention (PCI) and in-hospital mortality. (A) In-hospital mortality in both male and female patients simply increased with aging. (B) When dividing the patients into 2 groups according to survival to discharge and death during hospitalization, the sex difference in younger population was evident only in the patients who survived to discharge. 


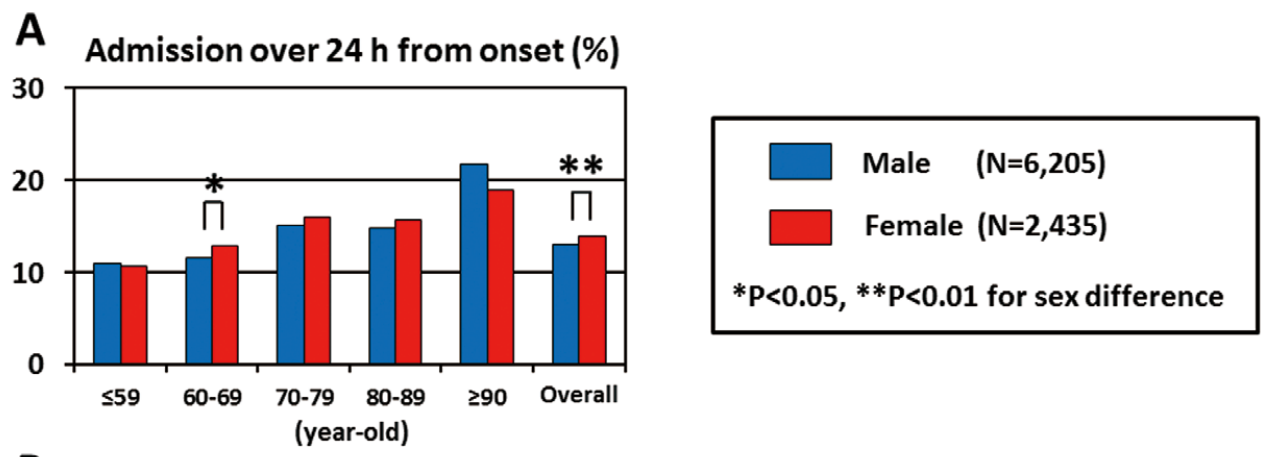

B Non-performance rate of primary PCl (\%)
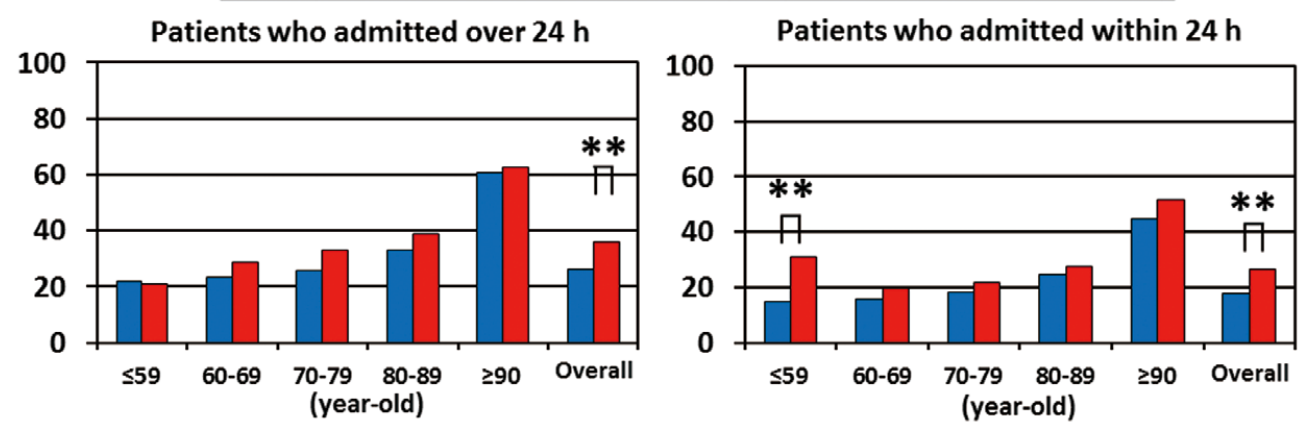

Figure 6. Sex differences in non-performance rate of primary primary percutaneous coronary intervention ( $\mathrm{PCl})$ and prehospital delay. (A) Prevalence of admission more than $24 \mathrm{~h}$ from symptom onset simply increased in both male and female patients with aging. (B) When dividing the patients into 2 groups according to admission more than or within $24 \mathrm{~h}$ of onset, the sex difference in the younger population was evident only in the patients who were admitted within $24 \mathrm{~h}$ of onset.

admission $\geq 24 \mathrm{~h}$ from symptom onset (Figure 6). These results suggest that the sex differences in non-performance rate of primary PCI noted in the younger age groups were less related to disease severity of AMI or delay for the therapy.

\section{Discussion}

The novel findings of the present study were as follows: (1) AMI patients who did not undergo primary PCI in Japan in the stent era were characterized by coexistence of symptomatic HF on admission, female sex, prior MI, onset at night, older age, and admission from onset $>24 \mathrm{~h}$; (2) when analyzed by age, the non-performance rate of primary PCI in female patients showed a U-shaped prevalence, whereas it simply increased with aging in male patients, and (3) in the younger population aged $<60$ years, female AMI patients had a significantly higher non-performance rate of primary PCI as compared with male patients independent of disease severity or delay from symptom onset to hospital arrival. These results indicate that there are substantial sex differences in the circumstances surrounding primary PCI, which remain to be resolved in order to further improve critical care of AMI in Japan.

\section{Performance Rate of Primary PCI in Japan}

In the present study, the performance rate of primary PCI in AMI patients was $78.3 \%$, which is higher than in other Western countries; in the GRACE and the NRMI studies, only $44 \%$ and $43.2 \%$, respectively, of STEMI patients underwent primary PCI. ${ }^{11,12}$ The high performance rate of primary PCI in Japan could be explained by the following. First, Japan is a relatively small country geographically, with good access to hospitals for the entire population. Second, in Japan, not only high-volume centers but also a number of low-volume ones have their own cardiac catheterization facility and perform primary PCI. ${ }^{14,20}$ Thus, access to a PCI-equipped hospital for AMI patients in Japan is more feasible than in Europe or USA. Third, because the cost of primary PCI is fully covered by the healthcare system operated by the Japanese government, AMI patients do not hesitate for economic reasons to visit hospital in Japan. The PACIFIC registry conducted between 2008 and 2011 at 96 hospitals in Japan demonstrated that the performance rate of primary PCI in patients with STEMI or NSTEMI was $95.6 \%$ and $90.4 \%$, respectively, ${ }^{14}$ which was even higher than in the present study. This discrepancy in the performance rate of primary PCI between the PACIFIC registry and the MIYAGI-AMI Registry Study could be explained in part by the difference in the study populations. The PACIFIC registry enrolled AMI patients from selected regional core hospitals that had facilities for advanced interventional therapy, whereas we enrolled AMI patients from communitybased hospitals. Moreover, the characteristics of the study populations may also cause a discrepancy because the patients in the present study were older and had a higher proportion of females as compared with the PACIFIC registry (median age, 70 years vs. 66 years; female, $28 \%$ vs. $22 \%$ ). Taken together, the present findings would more reflect the actual state of critical care for AMI patients in Japan. 


\section{Factors Influencing Non-Performance Rate of Primary PCI}

Previous studies from Western countries have demonstrated several factors associated with no reperfusion therapy in AMI patients, including higher age, female sex, pre-existing cardiovascular conditions such as prior MI or HF, history of diabetes, left bundle-branch block, lack of chest pain at presentation, delay from symptom onset to hospital arrival, and out-ofhours presentation. ${ }^{11,21,22}$ Indeed, most of these findings are consistent with the present study. Moreover, it has been noted that AMI patients presenting with HF are less likely to be treated with reperfusion therapy and have a higher risk of inhospital mortality. ${ }^{23-25}$ Similarly, in the present study, $43.4 \%$ of male and $54.9 \%$ of female patients with HF on admission did not undergo primary PCI, and multivariate analysis showed that $\mathrm{HF}$ on admission correlated most positively with non-performance of primary PCI. Furthermore, several studies have reported that mortality reduction by reperfusion therapies, especially by primary PCI, can be fully expected and appears most evident among high-risk patients with prior MI, older age or $\mathrm{HF},{ }^{26-28}$ a consistent finding of the present study. Thus, the optimal and aggressive approach using primary PCI for high-risk AMI patients appears to improve their prognosis.

\section{Sex Difference in the Non-Performance Rate of Primary $\mathrm{PCl}$}

In the present study, female patients underwent primary PCI less frequently than male patients. From the present results and previous reports, the sex difference in the non-performance rate of primary PCI could be explained by the following factors. First, prolonged delay in presentation, because of the atypical symptoms in female patients, ${ }^{27,29}$ could prevent them from having primary PCI during the optimal time for the procedure. Second, female AMI patients are older and have more comorbidities than male patients, ${ }^{27,29}$ making cardiologists hesitate to perform primary PCI. Third, it is known that female patients have non-obstructive coronary artery disease more frequently than male patients. ${ }^{30}$ Indeed, a recent study reported that $25 \%$ of acute coronary syndrome patients had no culprit lesion, characterized by younger age, female sex and high prevalence $(\sim 50 \%)$ of coronary spasm. ${ }^{31}$ These pathophysiological features of female AMI patients may result in the lower rate of primary PCI. Importantly, the present study showed for the first time that the non-performance rate of primary PCI showed a U-shaped distribution only in female patients when analyzed by age, whereas it simply increased with age in male patients. However, the sex difference in the performance rate of primary PCI, especially in the younger population, was not associated with prehospital delay or disease severity as evidenced by HF on admission and in-hospital mortality, whereas these factors themselves were strongly related to the non-performance of primary PCI. Actually, as shown in Figure $\mathbf{S} 2$, female patients aged $\leq 59$ years without primary PCI tended to have lower in-hospital mortality and shorter prehospital delay, as compared with male patients of similar age. Based on these findings, the sex difference in the non-performance rate of primary PCI noted in the present study could partly reflect sex differences in the pathogenesis of AMI.

\section{Study Limitations}

Several limitations should be mentioned. First, although almost all AMI patients were transferred to participating hospitals in the Miyagi prefecture, all patients in the Miyagi prefecture may not be registered. Second, in the present study, we were unable to distinguished patients with STEMI and
NSTEMI because of the registration system. It is possible that patients with NSTEMI underwent primary PCI less frequently than those with STEMI, ${ }^{32}$ which might have affected the present results. Third, as the MIYAGI-AMI Registry Study does not include angiographic data, we were unable to examine the performance rate of diagnostic coronary angiography and the influence of angiographic findings on the performance status of primary PCI in AMI patients. Fourth, management decisions, including the selection of reperfusion therapy, were left to the discretion of each attending physician in the MIYAGIAMI Registry Study, so we do not know the reasons why fibrinolytic therapy was chosen for some of the patients without primary PCI.

\section{Conclusions}

In the current PCI era, various factors, including age, HF on admission and sex, are associated with non-performance of primary PCI, and remain to be resolved in order to further improve the critical care of AMI in Japan.

\section{Acknowledgments}

This study was supported in part by the grants-in-aid from the Miyagi Prefecture and the Miyagi Medical Association, Japan. We thank all the collaborators in the MIYAGI-AMI Registry Study (Appendix). We also thank Yuki Kobayashi for excellent secretarial assistance.

\section{Disclosures}

Conflict of Interest: None declared.

\section{References}

1. Fibrinolytic Therapy Trialists' (FTT) Collaborative Group. Indications for fibrinolytic therapy in suspected acute myocardial infarction: Collaborative overview of early mortality and major morbidity results from all randomised trials of more than 1000 patients. Lancet 1994; 343: $311-322$.

2. Grines CL, Browne KF, Marco J, Rothbaum D, Stone GW, O'Keefe $\mathrm{J}$, et al. A comparison of immediate angioplasty with thrombolytic therapy for acute myocardial infarction: The Primary Angioplasty in Myocardial Infarction study group. N Engl J Med 1993; 328: $673-$ 679.

3. Michels KB, Yusuf S. Does PTCA in acute myocardial infarction affect mortality and reinfarction rates?: A quantitative overview (meta-analysis) of the randomized clinical trials. Circulation 1995; 91: $476-485$.

4. O'Gara PT, Kushner FG, Ascheim DD, Casey DE Jr, Chung MK, de Lemos JA, et al. 2013 ACCF/AHA guideline for the management of ST-elevation myocardial infarction: A report of the American College of Cardiology Foundation/American Heart Association Task Force on Practice Guidelines. J Am Coll Cardiol 2013; 61: e78e140, doi:10.1016/j.jacc.2012.11.019.

5. Steg PG, James SK, Atar D, Badano LP, Blomstrom-Lundqvist C, Borger MA, et al. ESC Guidelines for the management of acute myocardial infarction in patients presenting with ST-segment elevation. Eur Heart J 2012; 33: 2569-2619.

6. Keeley EC, Boura JA, Grines CL. Primary angioplasty versus intravenous thrombolytic therapy for acute myocardial infarction: A quantitative review of 23 randomised trials. Lancet 2003; 361: $13-20$.

7. Luepker RV, Raczynski JM, Osganian S, Goldberg RJ, Finnegan JR Jr, Hedges JR, et al. Effect of a community intervention on patient delay and emergency medical service use in acute coronary heart disease: The Rapid Early Action for Coronary Treatment (REACT) trial. JAMA 2000; 284: 60-67.

8. Aversano T, Aversano LT, Passamani E, Knatterud GL, Terrin ML, Williams DO, et al. Thrombolytic therapy vs primary percutaneous coronary intervention for myocardial infarction in patients presenting to hospitals without on-site cardiac surgery: A randomized controlled trial. JAMA 2002; 287: 1943-1951.

9. Grines CL, Westerhausen DR Jr, Grines LL, Hanlon JT, Logemann TL, Niemela M, et al. A randomized trial of transfer for primary angioplasty versus on-site thrombolysis in patients with high-risk myocardial infarction: The Air Primary Angioplasty in Myocardial 
Infarction Study. J Am Coll Cardiol 2002; 39: 1713-1719.

10. Andersen HR, Nielsen TT, Rasmussen K, Thuesen L, Kelbaek H, Thayssen P, et al. A comparison of coronary angioplasty with fibrinolytic therapy in acute myocardial infarction. N Engl J Med 2003; 349: $733-742$.

11. Eagle KA, Nallamothu BK, Mehta RH, Granger CB, Steg PG, Van de Werf F, et al. Trends in acute reperfusion therapy for ST-segment elevation myocardial infarction from 1999 to 2006: We are getting better but we have got a long way to go. Eur Heart J 2008; 29: 609-617.

12. Gibson CM, Pride YB, Frederick PD, Pollack CV Jr, Canto JG, Tiefenbrunn AJ, et al. Trends in reperfusion strategies, door-toneedle and door-to-balloon times, and in-hospital mortality among patients with ST-segment elevation myocardial infarction enrolled in the National Registry of Myocardial Infarction from 1990 to 2006. Am Heart J 2008; 156: 1035-1044.

13. Takii T, Yasuda S, Takahashi J, Ito K, Shiba N, Shirato K, et al. Trends in acute myocardial infarction incidence and mortality over 30 years in Japan: Report from the MIYAGI-AMI Registry Study. Circ J 2010; 74: $93-100$

14. Daida H, Miyauchi K, Ogawa H, Yokoi H, Matsumoto M, Kitakaze $\mathrm{M}$, et al. Management and two-year long-term clinical outcome of acute coronary syndrome in Japan: Prevention of Atherothrombotic Incidents Following Ischemic Coronary Attack (PACIFIC) Registry. Circ J 2013; 77: 934-943.

15. Hao K, Yasuda S, Takii T, Ito Y, Takahashi J, Ito K, et al. Urbanization, life style changes and the incidence/in-hospital mortality of acute myocardial infarction in Japan: Report from the MIYAGI-AMI Registry Study. Circ J 2012; 76: 1136-1144.

16. Sakurai K, Watanabe J, Iwabuchi K, Koseki Y, Kon-no Y, Fukuchi $\mathrm{M}$, et al. Comparison of the efficacy of reperfusion therapies for early mortality from acute myocardial infarction in Japan: Registry of Miyagi Study Group for AMI (MsAMI). Circ J 2003; 67: 209-214.

17. Watanabe J, Iwabuchi K, Koseki Y, Fukuchi M, Shinozaki T, Miura $\mathrm{M}$, et al. Declining trend in the in-hospital case-fatality rate from acute myocardial infarction in Miyagi Prefecture from 1980 to 1999. Circ J 2001; 65: 941-946.

18. Hao K, Takahashi J, Ito K, Miyata S, Sakata Y, Nihei T, et al. Emergency care of acute myocardial infarction and the Great East Japan Earthquake Disaster. Circ J 2014; 78: 634-643.

19. Tunstall-Pedoe H, Kuulasmaa K, Amouyel P, Arveiler D, Rajakangas AM, Pajak A. Myocardial infarction and coronary deaths in the world health organization MONICA project: Registration procedures, event rates, and case-fatality rates in 38 populations from 21 countries in four continents. Circulation 1994; 90: 583-612.

20. Ui S, Chino M, Isshiki T. Rates of primary percutaneous coronary intervention worldwide. Circ J 2005; 69: 95-100.

21. Barron HV, Bowlby LJ, Breen T, Rogers WJ, Canto JG, Zhang Y, et al. Use of reperfusion therapy for acute myocardial infarction in the united states: Data from the National Registry of Myocardial Infarction 2. Circulation 1998; 97: 1150-1156.

22. Jneid H, Fonarow GC, Cannon CP, Palacios IF, Kilic T, Moukarbel $\mathrm{GV}$, et al. Impact of time of presentation on the care and outcomes of acute myocardial infarction. Circulation 2008; 117: 2502-2509.

23. Steg PG, Dabbous OH, Feldman LJ, Cohen-Solal A, Aumont MC, Lopez-Sendon J, et al. Determinants and prognostic impact of heart failure complicating acute coronary syndromes: Observations from the Global Registry of Acute Coronary Events (GRACE). Circulation 2004; 109: 494-499.

24. Spencer FA, Meyer TE, Gore JM, Goldberg RJ. Heterogeneity in the management and outcomes of patients with acute myocardial infarction complicated by heart failure: The National Registry of Myocardial Infarction. Circulation 2002; 105: 2605-2610.

25. Wu AH, Parsons L, Every NR, Bates ER. Hospital outcomes in patients presenting with congestive heart failure complicating acute myocardial infarction: A report from the second National Registry of Myocardial Infarction (NRMI-2). J Am Coll Cardiol 2002; 40: 1389-1394.

26. Balzi D, Barchielli A, Santoro GM, Carrabba N, Buiatti E, Giglioli $\mathrm{C}$, et al. Management of acute myocardial infarction in the real world: A summary report from the AMI-Florence Italian Registry. Intern Emerg Med 2008; 3: 109-115.

27. Koeth O, Zahn R, Gitt AK, Bauer T, Juenger C, Senges J, et al. Clinical benefit of early reperfusion therapy in patients with STelevation myocardial infarction usually excluded from randomized clinical trials (results from the Maximal Individual Therapy in Acute Myocardial Infarction Plus [MITRA Plus] registry). Am J Cardiol
2009; 104: 1074-1077.

28. Parker AB, Naylor CD, Chong A, Alter DA. Clinical prognosis, preexisting conditions and the use of reperfusion therapy for patients with ST segment elevation acute myocardial infarction. Can J Cardiol 2006; 22: 131-139.

29. Cohen M, Gensini GF, Maritz F, Gurfinkel EP, Huber K, Timerman $\mathrm{A}$, et al. The role of gender and other factors as predictors of not receiving reperfusion therapy and of outcome in ST-segment elevation myocardial infarction. J Thromb Thrombolysis 2005; 19: 155161.

30. Anderson RD, Pepine CJ. Gender differences in the treatment for acute myocardial infarction: Bias or biology? Circulation 2007; 115: $823-826$.

31. Ong P, Athanasiadis A, Hill S, Vogelsberg H, Voehringer M, Sechtem U. Coronary artery spasm as a frequent cause of acute coronary syndrome: The CASPAR (Coronary Artery Spasm in Patients with Acute Coronary Syndrome) study. J Am Coll Cardiol 2008; 52: $523-527$.

32. Okura N, Ogawa H, Katoh J, Yamauchi T, Hagiwara N. Long-term prognosis of patients with acute myocardial infarction in the era of acute revascularization (from the Heart Institute of Japan Acute Myocardial Infarction [HIJAMI] registry). Int J Cardiol 2012; 159: $205-210$.

\section{Appendix}

\section{List of Participating Hospitals and Investigators}

Fukaya Hospital: Hiroshi Akiho, MD; Hikarigaoka Spellman Hospital: Sanae Shimura, MD; Ishinomaki Medical Association, Ishinomaki Municipal Hospital: Kenjiro Akai, MD; Ishinomaki Red-Cross Hospital: Hiroyasu Sukegawa, MD; Japan Community Health Care Organization Sendai Hospital: Yoshichika Oikawa, MD; Japan Community Health Care Organization Sendai South Hospital: Yasushi Hanadate, MD; JR Sendai Hospital: Mitsumasa Fukuchi, MD; Katta General Hospital: Hiroyuki Kanno, MD; Kesen-numa Hospital: Kazunori Ogata, MD; Kurihara Central Hospital: Kenjiro Akai, MD; Labour Welfare Corporation Tohoku Rosai Hospital: Hiroshi Kato, MD; Marumori National Health Insurance Hospital: Masataka Otomo, MD; Miyagi Cancer Center: Naoki Owada, MD; Miyagi Cardiovascular and Respiratory Center: Tatsuya Komaru, MD; Miyagi Eastern Cardiovascular Medicine: Yuichi Kikuchi, MD; Miyagi Northern Cardiovascular Center: Yukoh Wada, MD; Mori Hospital: Akio Mori, MD; Nagamachi Hospital: Hidetoshi Mitobe, MD; Nishitaga National Hospital: Akira Miura, MD; NTT East Tohoku Hospital: Aki Yamada, MD; Oizumi Memorial Hospital: Yoshirou Koiwa, MD; Osaki Citizen Hospital: Tetsuya Hiramoto, MD; Saito Hospital: Kenji Otsuka, MD; Saka General Hospital: Atsushi Obata, MD; Sendai Cardiovascular Center: Shin-ya Fujii, MD; Sendai City Hospital: Tetsuo Yagi, MD; Sendai Kosei Hospital: Taiichiro Meguro, MD; Sendai Medical Center: Tsuyoshi Shinozaki, MD; Sendai Open Hospital Sendai City Medical Center: Atsushi Kato, MD; Sendai Red-Cross Hospital: Akihiko Sugimura, MD; Sendai Tokushukai Hospital: Kimihiko Ogata, MD; Sen-en General Hospital: Ryoichi Hashiguchi, MD; Shichigashuku National Health Insurance Clinic: Takahiro Nagashima, MD; Shiogama City Hospital: Jun Goto, MD; South Miyagi Medical Center: Kan-ichi Inoue, MD; Southern Tohoku General Hospital: Masayoshi Terashima, MD; Tohoku Kosai Hospital: Shu Suzuki, MD; Tohoku Pharmaceutical University Hospital: Yoshiaki Katahira, MD; Tohoku University Hospital: Department of Cardiovascular Medicine, Hiroaki Shimokawa, MD; Department of Cardiovascular Surgery, Yoshikatsu Saiki, MD; Department of Medical Engineering and Cardiology, Institute of Development, Aging and Cancer, Tomoyuki Yanbe, MD; Tome Citizen Hospital: Munehiko Ishii, MD; Toyama Clinic on Tome City: Satoshi Sugawara, MD.

\section{Supplementary Files}

Supplementary File 1

Figure S1. Non-performance rate of primary percutaneous coronary intervention (PCI) by sex and age during every 3-year period of the study (2002-2004, 2005-2007, and 2008-2010).

Figure S2. Sex differences in acute myocardial infarction (AMI) patients who did not undergo primary percutaneous coronary intervention (PCI).

Please find supplementary file(s);

http://dx.doi.org/10.1253/circj.CJ-15-0440 